\title{
LÍNEAS DE CRONOS Y AIÓN Sobre la expresión del tiempo en el planeamiento urbano
}

\author{
Autor: Pablo Arráez Monllor \\ Filiación institucional: Universidad de Sevilla. Escuela Técnica Superior de Arquitectura / I.U.A.C.C. \\ Director de la tesis: Antonio Barrionuevo Ferrer \\ Mail: pabarrmon@alum.us.es
}

\section{RESUMEN.}

La presente investigación aborda el problema contemporáneo de la conceptualización de la expresión gráfica encaminada a la intervención en lo urbano. Su objetivo es reflexionar sobre la actividad creativa orientada a la producción de espacio y tiempo.

Para ello, se examina la capacidad de los diagramas de dar respuesta a uno de los grandes retos de la planificación urbana: La incorporación del cambio, de la diferencia, de la duración.

Palabras clave: Lo urbano, representación, diagramas, tiempo.

\section{ABSTRACT.}

This article is about the contemporary problem of the graphic expression conceptualization of the the urban. The aim is to reflex on the creative activity oriented to the production of space and time from creative approaches.

With that aim, it is examined the ability of diagrams to deal one of the big challenge of urban planning: The incorporation of change, the difference, la durée.

Key words: The urban, representation, diagrams, time. 


\section{Introducción.}

Habitamos lo urbano, un rizoma-canal que se superpone al árbol-raíz, sistemas ambos físicos y mentales que producen lo múltiple y lo Uno, y que siguen un modelo que no cesa de construirse y de desaparecer.

Se trata de un hábitat que se reconfigura indefinida e improgramablemente. Sometido a lo imprevisible, a lo que opera desde la inabarcable multiplicidad de los flujos. ¿Es posible entonces su planeamiento? Resulta necesario pensarlo con nuevos conceptos, en conjunción con una filosofía orientada a la creación.

Necesitamos pues una arquitectura de éste, nuestro tiempo. Que lo incorpore (que le de cuerpo) en el devenir de los acontecimientos (de lo puramente potencial). Una arquitectura de la duración, ajena a la ilusión de la representación (la traducción al presente de lo que es movimiento).

Y es que habitamos un tiempo nuevo que, liberado de su figura circular y cíclica (Cronos), se despliega en una línea (Aión), fuera de sus antiguos goznes, como forma vacía y pura. Y la modernidad es la asunción positiva de esta nueva dinámica.

Es por ello preciso poder transitar del acto a la potencia (asumir los acontecimientos en tanto que tales), transitar del tiempo del ser (en cuanto ser): Cronos, al tiempo del (ser en cuanto) devenir: Aión. Dicho de otro modo: Pensar desde los cuerpos, considerados como causas, hacia lo ideal, considerado como efecto: Éste parece un marco conceptual apropiado para abordar lo relacional y los procesos de participación en la arquitectura contemporánea.

La producción espacial de lo urbano en su devenir es entonces uno de los retos del planeamiento contemporáneo. El planeamiento como herramienta interactiva para la incesante transformación de un mundo en constante deriva. Un mundo del que se retroalimenta.

Uno de los dispositivos de este planeamiento son los diagramas: Máquinas abstractas (productoras de relaciones) que subyacen en los procesos generadores de estructura, y que, conceptualmente, se expresan mediante el mínimo elemento grafico.

Ejemplo de concepto diagramático contemporáneo es el del urbanismo infraestructural, en tanto que "creación de campos dirigidos", de matrices espaciales capaces de unificar, desde lo relacional, diversos elementos respetando al mismo tiempo la identidad de cada uno de ellos. De marcos para el desarrollo urbano diverso que ha de ocurrir a lo largo del tiempo.

Estamos inmersos en un proceso de grandes cambios, por lo que hay que atenderlo desde fundamentos creativos, de innovación que emerja desde la tradición. De ahí la importancia, en el ámbito del urbanismo, del establecimiento de ficciones, de imágenes que prefiguran las condiciones de lo real. Virtualidades, no abstracciones. Aquello que hace real lo real. El proyecto como labor creativa.

Resulta por tanto necesario atender a lo virtual, ese diagrama que, junto con lo actual, constituye lo real. Intuir (desde la imaginación creadora) los esquemas dinámicos que posibilitan la creación de nuevos espacios y tiempos.

Y ésta es una tarea urgente, pues nuestras ciudades están iniciando un proceso de transformación radical, impulsado por la tecnología digital, que va de la mano de una manifiesta ausencia de perspectiva histórica, en favor de un presente eterno (Cronos).

La investigación que aquí se presenta pretende verificar la capacidad de los diagramas para responder a ese reto.

\section{La representación de lo urbano.}

\subsection{El concepto de lo urbano.}

Solà-Morales (2002: 40-53) caracteriza la realidad material del fenómeno metropolitano finisecular como "enormes concentraciones urbanas que ya no pueden ser pensadas como ciudades en el sentido convencional del término", por tratarse de una auténtica "colisión de innumerables fuerzas que (...) tienden a extenderse ilimitadamente sin otra forma más que la que le proporcionan elementos geográficos o algunas 
grandes infraestructuras".

Así, la forma de la metrópoli, que se desarrolla en torno a "grumos urbanos" que, en la mayoría de los casos, no obedecen a un plan previamente establecido, se hace "mórbida y maleable". Y es que se ha generalizado una formación inestable en el tiempo, que parece moldearse "a tenor de las acciones y reacciones que las distintas operaciones plantean". Por ello, concluye este autor, percibimos una acumulación de acontecimientos que identificamos como propios de nuestro tiempo, "de su dinamismo más activo". Pero, a su vez, advertimos nuestra limitada capacidad para darles respuesta.

Y es que, como también señalara este autor (Ibíd.: 156-157), la metrópoli sin límites ya no es comprensible en base al orden de los trazados que, históricamente, posibilitaban una inteligibilidad estable. Por contra, la condición imprevisible de la ciudad se ha convertido en su verdadero "modo de exposición", siendo ello consecuencia de una dinámica inclusiva y contradictoria por la cual se apropia de todas sus energías a la par que de sus conflictos.

Resulta por tanto preciso el entendimiento de lo urbano en toda su complejidad. Lo urbano en la acepción que H. Lefebvre le dio al término (M. Lorea, 2013: 15): Lo que persiste de la ya desaparecida ciudad tradicional. Su proceso, su horizonte, su práctica.

Y es que nos encontramos ante la disolución de toda forma urbis tradicional, de toda identidad urbana, un proceso que se lleva a cabo en los territorios indefinidos que habitamos hoy día: La ciudad-territorio (Cacciari, 2010:31-45). Dicho de otro modo: La ciudad está en todas partes, luego ya no existe, lo que hay es un espacio urbano indefinido, homogéneo, indiferenciado, en el que desaparece la dimensión del lugar, donde los acontecimientos suceden sobre la base de lógicas que ya no responden a ningún proyecto global unitario. Es el espacio de la movilización universal, de la superación del vínculo espacial, de la desterritorialización.

Pero habitarlo no es posible si no se dispone para ello, si no proporciona lugares. Los necesitamos por nuestra propia naturaleza: Somos lugares, nuestro cuerpo es nuestro lugar fundamental. Nos encontramos, pues, ante una contradicción a afrontar para poder comprenderla y vivirla: A mayor deseo de ubicuidad y emanación de energía "antiespacial", mayor inmovilización de los cuerpos (por saturación del espacio) y mayor exigencia psíquica de fuertes presencias arquitectónicas, significativas y simbólicas.

No obstante lo anterior, esta ciudad-territorio no es del todo ininteligible, pues se desarrolla siguiendo procesos concretos (Martí, 2006:24) de dispersión territorial y, a su vez, de concentración de las funciones principales en algunos polos significativos. El resultado es, según este análisis, una estructura territorial intensamente interrelacionada, un territorio en red. Una ciudad policéntrica.

Ahora bien, dichas polaridades (Ibíd.: 53) "cada vez más pueden organizarse en cualquier lugar, rechazando toda malla funcional preconstruida". Se constituye así una ciudad ajerárquica (no necesariamente caótica), conformada por estructuras parciales e inestables, por multiplicidades irreductibles a una figura única. Y, precisamente por ello, dotada de "la fuerza de las uniones débiles" (Ascher, 2012).

Pero no estamos ante una multiplicación del sistema urbano convencional de agrupaciones en torno a un centro (y por ello el diagrama de ciudad jardín de E. Howard ya no es una referencia). La naturaleza de las citadas polaridades es otra pues, como afirma H. Le Bras (citado por F. Choay en Martín, 2009:70) "el paso de una geografía de polos a una geografía de líneas significa la modernización". Y es que, indica esta autora, la era de las entidades urbanas discretas ha terminado, pues la "comunicabilidad universal" anunciada por Cerdá y Giovannoni es también la de la urbanización universal, difusa y explosionada.

Así, prosigue Choay, la dinámica de las redes de servicios tiende a sustituir a la estática de los lugares edificados para condicionar mentalidades y comportamientos urbanos. De este modo, las relaciones que mantienen nuestras sociedades con el espacio, el tiempo y las personas se ciernen en torno a un sistema de referencia físico y mental, constituido por redes materiales e inmateriales, así como por objetos técnicos, cuya manipulación pone en juego un repertorio de imágenes y de informaciones. A este sistema operativo, válido y factible en cualquier lugar, se le puede llamar lo Urbano.

No nos encontramos ya, por tanto, ante una dialéctica de centro y periferia, ni de núcleos y ejes de interconexión, sino ante una dinámica rizomática: Extensiones superficiales ramificadas en todas direcciones (redes), que generan concreciones (nodos) allá donde se producen incrementos (siempre temporales) de intensidad urbana. 


\subsection{El problema de la representación.}

El urbanismo contemporáneo se desarrolla a la par que la arquitectura líquida, un auténtico "desplazamiento de los paradigmas vitrubianos", conceptualizado en base al pensamiento de $\mathrm{H}$. Bergson sobre la "experiencia de la duración" (Solá-Morales Ibíd.:123-135): "Precisamente porque en nuestra cultura contemporánea atendemos prioritariamente al cambio (...) ya no podemos pensar en recintos firmes, establecidos por materiales duraderos, sino en formas fluidas, cambiantes, capaces de in-corporar (...) lo cambiante, no buscando una definición fija y permanente de un espacio, sino dando forma física al tiempo, a una experiencia de durabilidad en el cambio (...) Una arquitectura líquida".

Se trata en definitiva de una arquitectura capaz de "manipular la contingencia de los acontecimientos". Pero dado que "la experiencia del lugar del flujo es cinestésica", el uso de la representación perspectiva es completamente equivocado. Necesitamos pues " instrumentos de control de este espacio/tiempo/evento que es el lugar del flujo", por lo que uno de los retos fundamentales para la arquitectura contemporánea es representar, de forma global, "la experiencia del fluir en el movimiento metropolitano, la deriva que se aleja de la programación y la regulación preestablecidas".

Un ejemplo pionero en la representación del fluir en lo urbano fue el presentado por L. Kahn en 1953, en sus Estudio de flujos de tráfico en Philadelphia. En ellos (Brownlee y De Long 2000:62), el movimiento se representa mediante la diferenciación de sus elementos individuales (vehículos y peatones), cada uno identificado con una flecha cuyo tamaño y frecuencia es proporcional a su escala y velocidad. Seguidamente, estos elementos se ensamblan en la totalidad planimétrica del trazado urbano, expresándose así no el espacio en sí, sino los diferentes canales de flujos. Pero, como añade Solá-Morales (Ibíd.: 132), estos bellos dibujos prueban las grandes limitaciones implícitas a la representación del movimiento, pues éste es un fenómeno que sólo puede conformarse desde dentro.

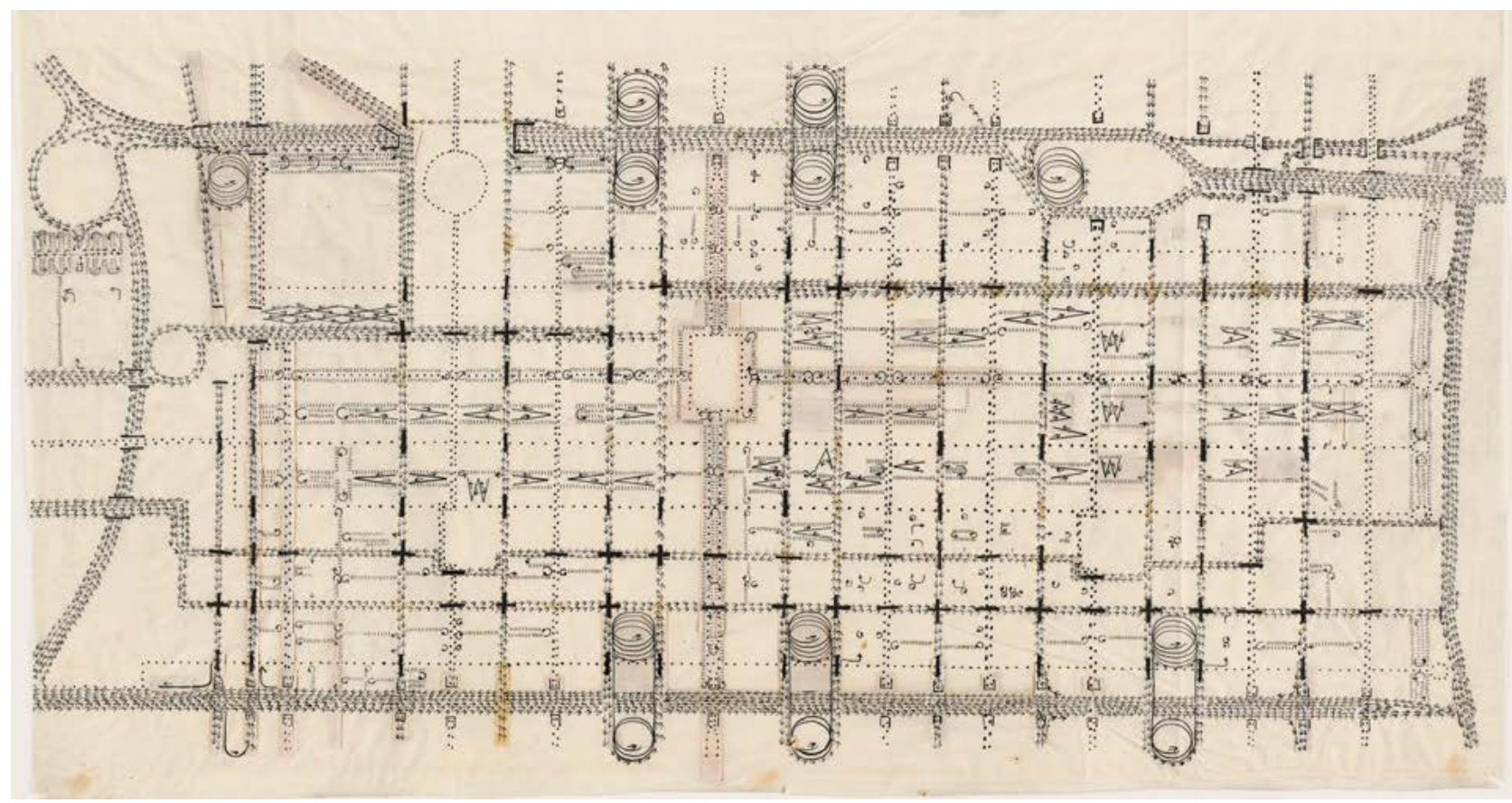

Estudio de flujos de tráfico para Philadelphia, 1953 (L. Kahn)

Fuente: "Khan" (Brownlee y De Long)

Con este ejemplo pretendemos mostrar que el problema de la representación en el urbanismo contemporáneo hay que encuadrarlo en el nuevo paradigma cultural que afecta al concepto mismo de representación.

Partamos de que (Ibíd.:57) "las formas de representación de la experiencia urbana no son resultado de una técnica ó de los cambios físicos que experimenta la ciudad a lo largo del tiempo", y que ello es así porque "la percepción es un fenómeno cultural y, por lo tanto, la representación de esta experiencia perceptiva está ligada a valores que la cultura establece como primordiales en determinado momento histórico". Es así que "la representación dominante del fenómeno urbano está vinculada a la representación artística y filosófica". 
Veamos entonces de qué manera plantea Deleuze la reformulación del concepto de representación (Pardo 2011:24-26): Cuando Bergson formuló su tesis de que el movimiento es "algo único que sucede entre dos paradas, pero que no se confunde con ellas ni puede reducirse a lo inmóvil", lo hizo porque consideró que "la representación del movimiento como una sucesión de paradas" produce una ilusión cuya causa es no sólo "la espacialización (geométrica) del movimiento" sino, de forma más profunda, el concepto clásico de cambio. Y formuló dicha crítica al pensamiento dominante por considerar que éste "parece ligado a la forma de lo actual", por lo que "el movimiento no puede pensarse si no es por mediación del reposo, la potencia no puede pensarse más que por mediación del acto, y a esta sumisión del movimiento al reposo (o de la potencia al acto) en el pensamiento es a lo que en rigor habría que llamar (...) representación". Y la representación así definida lleva aparejada una concepción del tiempo que "comporta necesariamente su subordinación al presente".

De esta manera, siendo la ciudad contemporánea cambio incesante, puede entonces considerarse su planificación, cuando se hace de manera estática, una suerte de representación ilusoria, ligada a la forma de lo actual.

Siendo así, ¿cuál cual sería esa nueva concepción filosófica a la que debe vincularse la representación del fenómeno urbano? Continuemos con la exposición de Pardo (2011: 31-33 y 37-43): Dado que "la opción filosófica a favor de el ser en cuanto ser" consiste en anclar el pensamiento en aquello que la naturaleza tiene de presencia, de actualidad y de reposo, puede formularse el pensamiento de Deleuze como un "movimiento que se dirige hacia el ser en cuanto no-ser", es decir, hacia "lo que tiene de ausencia, de potencialidad y de movimiento".

Así, para analizar "la oposición tradicional entre ser y devenir", Deleuze pone como ejemplo la proposición "Alicia crece" (procedente de Alicia en el País de las Maravillas, de L. Carroll), en tanto que predicado "puramente potencial", a lo cual denomina acontecimiento. Dibuja así "un escenario en el que la potencia (...) debe ser pensada solamente en cuanto potencia". Y desde este punto de partida reconstruye "la contraposición entre el tiempo del ser (en cuanto ser) y el tiempo del (ser en cuanto) devenir". Y lo hace mediante un proceso de inversión (del platonismo), planteando un movimiento "desde los cuerpos, considerados como causas, hacia lo ideal, considerado como efecto".

De esta forma, si entendemos las transformaciones urbanas como acontecimientos, esto es, como predicados puramente potenciales, cabe poner en duda el enfoque trascendente de los planes fundamentados en formas o modelos de ciudad como causas en sí. Se plantea entonces una inversión del concepto de urbanismo hacia lo inmanente (hacia procesos de abajo arriba), tal que opera con lo urbano en cuanto potencia: Desde las relaciones entre los cuerpos y las subjetividades (consideradas como causas), hacia el proyecto y el plan (que deviene así efecto).

Éste parece un punto de vista cabal para abordar lo relacional y los procesos de participación en la arquitectura contemporánea.

\subsection{La forma en el devenir.}

Si desde la óptica deleuziana (Rojo 2012:12) pensamos en la caracterización que hace Koolhaas (2006: 30-32) del modo en que se produce la Ciudad Genérica en tanto que "apoteosis de la elección múltiple" entre "infinitos márgenes ocultos, colosales reservas de inercia (y) un perpetuo proceso orgánico de ajuste", comprobamos la pertinencia de pensar la ciudad contemporánea desde el concepto de dispositivo. Esto es: Como "unidad multilineal de procesos en constante desequilibrio", procesos que, por tanto, pueden sufrir cambios de dirección ó derivaciones. Y si cabe entender la ciudad como dispositivo, es materialmente aplicable el enunciado de que "pertenecemos a los dispositivos y actuamos en ellos". Consideremos entonces que la actualidad de un dispositivo es "su novedad en relación a los anteriores", de modo que "lo nuevo es lo actual", por tanto, "lo actual no es lo que somos, sino aquello en lo que devenimos". En conclusión: El perpetuo proceso orgánico de ajuste de la ciudad-dispositivo es su devenir. La producción de la forma de lo urbano en su devenir es entonces uno de los retos del urbanismo contemporáneo.

Y es que la ciudad contemporánea se enmarca en el fenómeno mediante el cual el vértigo de la novedad que era propio de la modernidad sólida ha devenido en verdadero frenesí de la impermanencia en la actual etapa líquida. Se trata, en esencia del tránsito que nuestra cultura ha efectuado "desde un marco ontológico instalado en lo que podríamos llamar una metafísica de la sustancia", a otro que "con Deleuze podríamos 
llamar una ontología del devenir" (Arenas, 2011): "Ya no quedan parapetos, puentes, límites. Los modernos nos instalamos en la avalancha. Estamos habitando el desbordamiento y no hay manera de fijar los límites, y por tanto no se puede ya pensar a la manera antigua, donde era posible detener el movimiento y abordar las cosas en su estabilidad" (Rojo, Ibíd.:13).

Es necesario entonces pensar la ciudad, y el propio urbanismo, como realidad dinámica, y para ello resulta de interés seguir a Bergson y Deleuze en su ya esbozada concepción del movimiento (íbid.): "Lo que sucede (...) no es una colección de paradas, es un movimiento de una vez", y para describir ese movimiento, para pensarlo, es necesario hacerlo (...). Puede pensarse el ser en lo

que tiene de movimiento, de potencia, de devenir, y puede seguirse ese camino sin desembocar en el caos ni en lo informe". Es en este sentido en el que Solá-Morales señalaba que la representación del movimiento (del fluir metropolitano) sólo puede conformarse desde dentro.

\subsection{Trabajar por conceptos.}

Con todo lo anterior, hemos querido poner de manifiesto que la gran dificultad que actualmente implica el desempeño del urbanismo excede a las cuestiones disciplinarias, pues se motiva en una crisis mucho más profunda, que afecta al hecho mismo de planificar en la sociedad contemporánea.

Y es que, conforme a lo constatado por Bauman (2012:143-148) "todas las visiones de un mundo hecho a medida dibujadas hasta ahora resultan indigeribles, y todas las que aún no han sido dibujadas resultan sospechosas a priori, y es así que viajamos sin una idea de destino". Esta situación deriva, en parte, de la complejidad e incertidumbre propia de la actual era de modernidad líquida: En la medida en que se reduce nuestra capacidad de control del presente se minora nuestra capacidad de planificación del futuro.

Lo anterior explica el proceso en curso de reformulación del urbanismo, necesariamente apoyada en una amplia reflexión, más allá de sus límites tradicionales. Y es que "para entender plenamente nuestro destino y posición en el mundo tecnológico moderno no basta con la arquitectura" (Kwinter, 2009: 149), pues resulta necesaria la "conjunción con una filosofía sostenida y creativa, entendida no sólo como una forma de conocimiento, sino también como una forma de creación": Desde aquella nuestras capacidades conceptuales e inventivas podrán ponernos al nivel de las condiciones históricas, materiales y técnicas de nuestra época.

Necesitamos pues nuevos "planos de intersección" entre filosofía y arquitectura (Arenas y Fogué, 2011). Y es por ello pertinente el trabajo por conceptos (Deleuze).

Esbocemos entonces una nueva definición de planeamiento urbano. Para pensar en ello, consideremos cómo en el pensamiento urbanístico contemporáneo existe una convergencia en torno a la cultura de la transformación (Ezquiaga 2011), sustentada en parte, como ya hemos visto, en la deleuziana ontología del devenir (Arenas 2011). Parece entonces justificado que una caracterización de dicho pensamiento (Aragüés 1998) sea utilizada, directamente, para definir al planeamiento contemporáneo como una "herramienta interactiva para la incesante transformación de un mundo en constante deriva, que fluye con el ritmo vertiginoso de la realidad, permaneciendo únicamente la voluntad de construir".

Un planeamiento productivo (no reproductivo), afirmativo, y por tanto ajeno a cualquier labor representativa, a cualquier imagen dogmática, a la abstracción de la Idea. Un planeamiento que aspira a la articulación de inmanencia y trascendencia, en el que el sujeto (el lugar, cada proyecto, la iniciativa ciudadana o empresarial, etc.) se exprese y se pliegue como efecto de la intervención de un campo trascendental (fundamentado en los valores que afirma), que a su vez también resulta plegado por la potencia de la subjetividad. Un planeamiento que asume la importancia de la retroalimentación en la racionalidad contemporánea (Ascher 2012:32-33), entendida como dispositivo de ajuste de las causas por sus efectos, que posibilita modificar aquello que precede (el plan urbanístico, en la práctica habitual) por lo que sigue (los proyectos, su ejecución, la gestión del espacio urbano).

En este proyecto de investigación nos centraremos en el papel que los conceptos de diagrama y de tiempo ( $y$ su interrelación), juegan en el urbanismo contemporáneo, estudiándolos en base a las tradiciones culturales que los fundamentan.

\section{Líneas de Cronos y Aión.}

\subsection{Máquinas abstractas para los ensamblajes socio-espaciales.}


Llegado a este punto, parece necesario identificar sistemas de producción que operen conforme a lo anteriormente expuesto. Pero antes creemos pertinente reseñar la traducción que, a la disciplina arquitectónica, hace Dovey (2013:131-147) del deleuziano concepto de ensamblaje: Un todo formado por la interconectividad y los flujos entre sus partes constituyentes, un grupo socio-espacial de interconexiones. Su objetivo es establecer una forma útil de repensar la teoría del lugar en términos de proceso, de formación de identidades, de devenir. Y de manera esencialmente multidisciplinar y multiescalar.

La teoría del ensamblaje aspira a funcionar al modo de una caja de herramientas destinada a entender cómo funcionan los lugares en su continuo proceso de cambio. Para ello, el trazado creativo de mapas es una práctica clave, especialmente los diagramas, entendidos como máquinas abstractas (Deleuze y Guattari), como representación gráfica de conexiones, mapas de relaciones entre fuerzas inmanentes que son co-extensivos con el campo social completo. Abstractas porque son relacionales, y maquínicas porque son productoras de subjetividad.

También a nivel teórico, es destacable la lectura que hace De Landa (2011:14-15) respecto de los diagramas que subyacen en todos los procesos. En lo que concierne al quehacer humano, y partiendo del reconocimiento de que cualquier explicación de nuestra conducta "debe introducir entidades intencionales irreductibles, como las creencias y los deseos", este autor señala que, en algunos casos, nuestras decisiones están determinadas por la posición y el rol que tenemos en una organización jerárquica. De ello resultan decisiones centralizadas y la implementación de planes basados en ellas, los cuales dejan muy poco espacio para la autoorganización. Pero, en otros casos, lo que importa son "las consecuencias colectivas no intencionales de decisiones intencionales". Es en estos casos cuando podemos esperar que ocurra "generación espontánea de estructura".

En consonancia con lo anterior, este autor (Ibíd.:28) diferencia entre formaciones de jerarquías y de "embonajes", refiriéndose con este término a los "ensamblajes de componentes heterogéneos, en el que el todo posee propiedades que no están presentes en sus partes constituyentes, y en el que los componentes son encajados mediante complementariedades funcionales".

Pues bien, siempre siguiendo a este autor (Ibíd.:70-71), "existe un proceso físico común a la formación de embonajes y jerarquías que hace que cada uso particular de los dos términos se pueda tomar literalmente". Y añade "que estos procesos comunes no pueden ser capturados tan sólo por medio de representaciones ligüísticas, sino que necesitamos emplear algo cercano a los diagramas ingenieriles para dotarlos de una mayor especificidad". Dichos diagramas son las máquinas abstractas que subyacen en los procesos generadores de estructura, y que darán como resultado ensamblajes y jerarquías específicas.

Por otra parte Soriano (2002) propone, entre otras definiciones para el concepto de diagrama, la de "mínimo elemento grafico que explica un concepto", siendo también subrayable su énfasis en la naturaleza pragmática de dicho concepto: No se trata de esquemas, simplificaciones o dibujos preparatorios, sino que directamente se refieren al espacio, a la forma, al material que lo construye. $Y$ uno de sus constituyentes siempre es el tiempo, pues los diagramas conforman "estructuras graficas de pensamiento asociadas a un procedimiento", representaciones del curso de procesos dinámicos. Y aquí el origen deleuziano de esta concepción de lo diagramático se hace explícito: "[Su] relación con lo concreto es no-lineal y no determinista (...) Su definición paradigmática es la maquina abstracta".

Y en cuanto a la aplicabilidad del concepto, cabe aquí reseñar que, para este autor se trataría, en definitiva, de "liberar de nuestro control el resultado, para que el objeto arquitectónico puede establecerse por si solo".

\subsection{Las condiciones de campo en urbanismo.}

Un urbanismo que renuncia a establecer un modelo o diseño global de ciudad posibilita la incorporación de la contingencia y la operatividad permanente. Dicha renuncia, en cualquier caso, es acorde al signo de los tiempos pues, como señala Allen (2009:149-153,167-168), el proceso del "debilitamiento de la aspiración clásica de totalidad", viene ya dado por la "provisionalidad del todo" en la sociedad contemporánea.

Se plantea así el desarrollo de prácticas en que la forma global no sea fin sino consecuencia. Consecuencia de operar estratégicamente con las condiciones establecidas localmente, de modo que se priorice la obtención de espacios para el cambio, el accidente y la improvisación de los futuros usuarios. Esto implica una arquitectura que, frente a su tradicional investidura de "permanencia, estabilidad y certeza", asuma "la 
incertidumbre de lo real". Que sea capaz de dar forma a lo nuevo trabajando "con y no contra el lugar", al registrar "la complejidad de lo que viene dado".

Se propone para ello el establecimiento de condiciones de campo entendidas como "cualquier matriz formal o espacial capaz de unificar diversos elementos respetando al mismo tiempo la identidad de cada uno de ellos". De este modo, constituyen "conjuntos unidos de forma flexible que se caracterizan por su porosidad y conectividad interna": Lo que determina su comportamiento es la relación entre las partes. Por tanto, no funcionan ni mediante mallas reguladoras ni mediante relaciones convencionales de axialidad, simetría y jerarquía, pues sus condiciones constituyentes "son relacionales, no figurativas, y se basan en el intervalo y la medida". Como ejemplo genérico de condición de campo en el contexto urbano se señalan los elementos infraestructurales de la ciudad moderna, en su interconexión en redes abiertas.

Continúa este autor señalando la analogía existente entre este concepto de campo y los principios algebraicos de combinación que operan junto a los principios geométricos (jerárquicos) que fundamentan la arquitectura clásica occidental. Así, puede comprobarse que en otras tradiciones, junto a la organización de figuras en el espacio se trabaja con unidades numéricas combinadas, con relaciones que fijan la sintaxis interna, sin que exista un "andamiaje geométrico global". De esta forma (a diferencia de lo que ocurre cuando se trabaja desde el concepto clásico-occidental de unidad cerrada), resulta posible hacer modificaciones sin una transformación morfológica sustancial.

Como ejemplo paradigmático de estos principios algebraicos se señala la Mezquita de Córdoba, por cuanto que, pese a ser el resultado de cuatro procesos de ampliación desarrollados durante siglos, su estructura tipológica se mantuvo intacta, gracias a la permanencia de sus relaciones internas: Un espacio de culto cubierto, en el que sus diferentes elementos arquitectónicos, y los intervalos entre ellos, se entrelazan de modo preciso, abriéndose todo ello a un patio cerrado, flanqueado por un minarete.

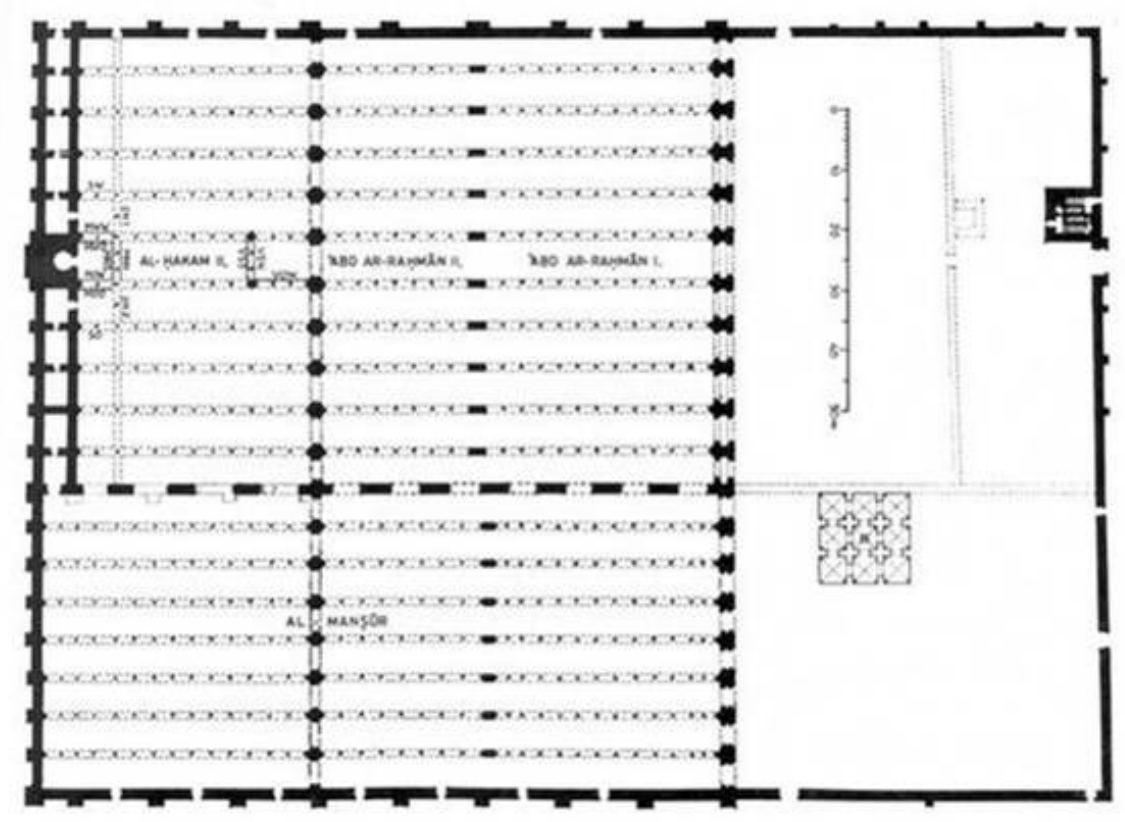

Planta de la Mezquita de Córdoba (Allen, 2009)

Por otra parte, este mismo autor (2010:176-181), en coherencia con todo lo anterior, plantea un giro hacia el urbanismo infraestructural, al cual caracteriza como "un nuevo modelo de praxis y un sentido renovado del potencial de la arquitectura para estructurar el futuro de la ciudad". Desde un "alejamiento del imperativo de la representación", plantea una vuelta a la instrumentalidad de la arquitectura mediante su dedicación "a propuestas concretas y estrategias realistas de puesta en práctica", como "forma de trabajar en la gran escala que escapa a las nociones sospechosas del planeamiento general y al ego heroico del arquitecto individual". Propone para ello la "creación de campos dirigidos en los que el programa, el acontecimiento y la actividad puedan desempeñar su papel con plenitud".

Concluye este autor que esta forma de abordar lo infraestructural posibilita, dada la singularidad de la 
arquitectura, estructurar la ciudad a la vez que "construir físicamente conceptos sociales y culturales" (en los que el inconsciente también jugaría su papel, al posibilitarse la realización de eventos ajenos al control de un autor individual).

A nuestro entender, se plantea con todo ello la configuración de campos a gran escala que estructuran el espacio urbano a la vez que posibilitan su producción desde lo inmanente. Ello implica un planeamiento que expresa, diagramáticamente, lógicas relacionales y sus conceptos subyacentes (que en tanto que tales, operan a modo de núcleos de estabilidad).

Un ejemplo brillante de este tipo de planes es el de Beigel y Architecture Research Unit para Stadtlandschaft Lichterfelde Süd, Berlin (ganador de un concurso internacional en 1998): Como señala Mead (2009: 183) citando a sus autores, plantea una alternativa al planeamiento general convencional al fundamentarse en "infraestructuras paisajísticas" como "un marco para el desarrollo urbano diverso que ocurra a lo largo del tiempo". Así, no es en absoluto casual que su conocido artículo sobre este proyecto se titule "Viajeros del tiempo".
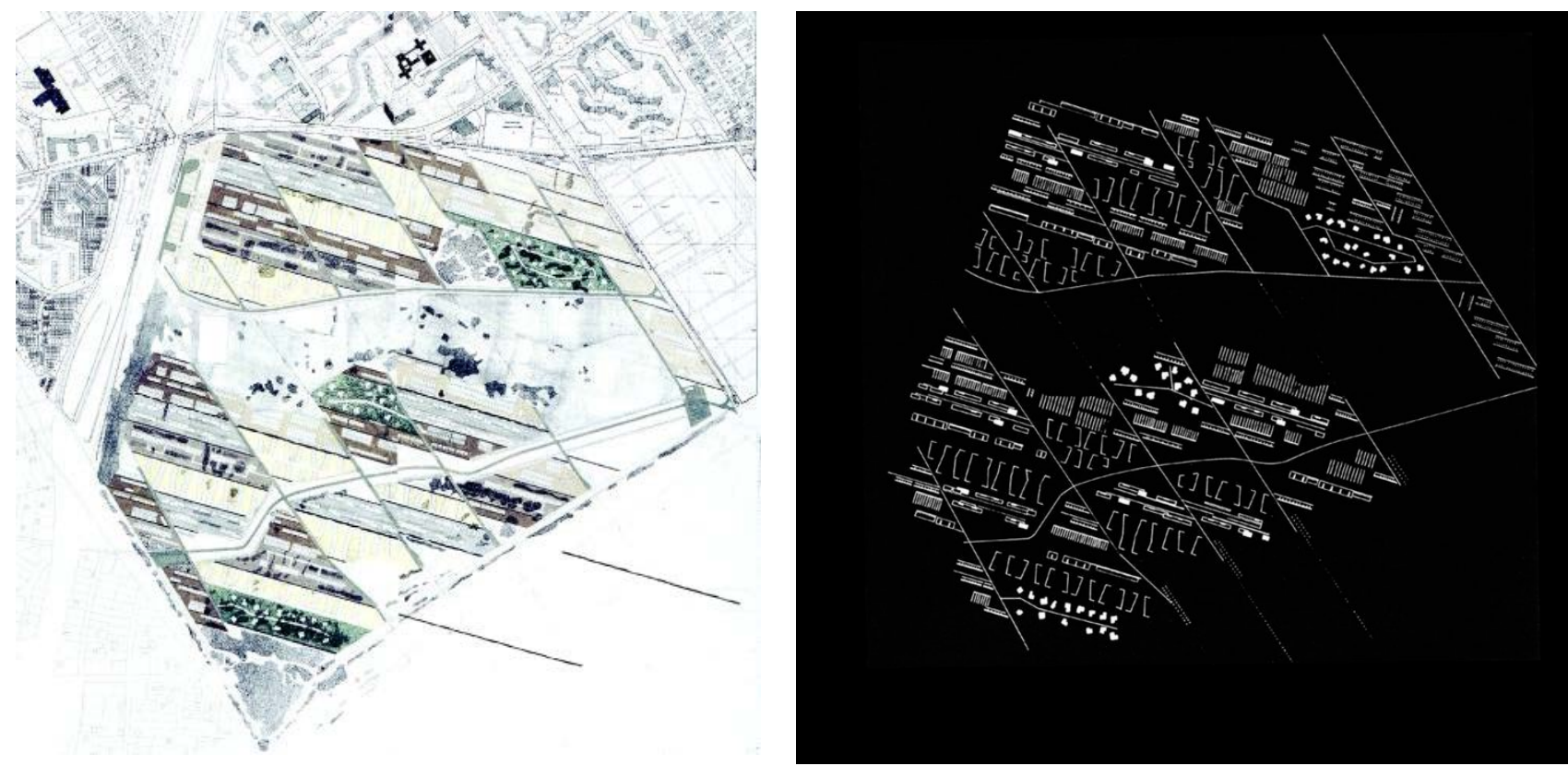

Plan Stadtlandschaft Lichterfelde Süd, Berlin (1998).

Plano de la "infraestructura [paisajística] urbana" y Diagrama del "menú residencial".

(F. Beigel y Architecture Research Unit: http://aru.londonmet.ac.uk/works/lichterfelde/)

\subsection{Líneas del tiempo.}

Habitamos un tiempo nuevo que (Pardo, Ibíd.:124-131), liberado de su figura circular y cíclica (Cronos), emancipado de los sucesos que constituían su contenido, ha invertido su relación con el movimiento y se ha descubierto como forma vacía y pura. Es tiempo que se despliega, en lugar de que algo se despliegue en él: Es la condición del movimiento (no lo que lo mide). Por ello, la nueva concepción del tiempo tiene que ser capaz de escapar de las coordenadas de la representación y corresponder al antes y después, para no plegarse a la figura del ahora. Apto para dar cuenta del devenir, del ser en cuanto no ser, la forma vacía y pura del tiempo ha desenrollado su círculo y, fuera de sus antiguos goznes, se extiende en una línea (Aión). El tiempo se ha salido de su curso, y ya nadie podrá volver a encajarlo en él. Y la modernidad, rectamente comprendida, es la asunción positiva de esta nueva dinámica.

La asunción de un nuevo modelo en términos de flujo. (Pardo, Ibíd.:274)

Hay (Pardo, Ibíd.:39,43) un tiempo de los cuerpos (Cronos), de las diferencias cuantitativas, donde todo es actual y presente. $\mathrm{Y}$ hay un tiempo de los acontecimientos (Aión), de los efectos de las causalidades corporales. El tiempo de las relaciones lógicas, de las distinciones cualitativas. Hay, como ya se ha dicho, un tiempo del ser (en cuanto ser) y un tiempo del (ser en cuanto) devenir: Cronos y Aión. Y debe poder transitarse del uno al otro, también del acto a la potencia: Desde los cuerpos actuales, hacia las relaciones temporales puras, vaciadas de su contenido físico. Debe poder transitarse desde los cuerpos, considerados como 
causas, hacia lo ideal, considerado como efecto.

Éste parece un marco conceptual apropiado para abordar lo relacional y los procesos de participación en la arquitectura de nuestro tiempo. Para una arquitectura que lo incorpore (que le de cuerpo) en el devenir de los acontecimientos (de lo puramente potencial). Una arquitectura de la duración, ajena a la ilusión de la representación (la traducción al presente de lo que es movimiento).

Resulta por tanto necesario atender a lo virtual (Pardo, Ibíd.: 90,93), ese diagrama que, junto con lo actual, constituye lo real, aquello que hace real lo real. Intuir (desde la imaginación creadora) los esquemas dinámicos que posibilitan la creación de nuevos espacios y tiempos, de nuevas posibilidades de vida y de pensamiento, de nuevas sensibilidades.

Y ésta es una tarea urgente, pues nuestras ciudades están iniciando un proceso de transformación radical (Picon, 2015:154), impulsado por la tecnología digital. Pero ésta va de la mano de una manifiesta ausencia de perspectiva histórica, en favor de un presente eterno (que aquí podemos identificar como Cronos), o de un futuro tan cercano a lo que ya conocemos, que parece una mera intensificación de las condiciones actuales (lo que aquí podemos denominar un futuro sin diferencia).

Es decir: La tecnología no puede resolver por sí sola la incorporación del nuevo tiempo: Éste es un problema cultural a resolver, entre otros medios, desde su expresión gráfica aplicada a lo urbano. La investigación que aquí se presenta pretende verificar la capacidad de los diagramas (entendidos como el mínimo elemento gráfico necesario para intervenir en la producción del espacio y del tiempo) para responder a ese reto.

Abordaremos diagramas como medios de expresión gráfica y procedimental conque definir, en base a lógicas relacionales, una sintaxis espacial posibilitadora de una multiplicidad de proyectos. En ellos proponemos la denominación de líneas de Cronos a las correspondientes a la geometría estática orientada hacia el pasado puro de la Idea, o hacia el presente eterno de la ciudad inteligente. Líneas de jerarquía (Landa). Líneas de las ciudades ideales (como las diagramáticas renacentistas), de la cuadrícula hispanoamericana (El sueño de un Orden), de las plazas mayores. Líneas de "axialidad simbólica" que responden a una necesidad de "reproducción social" (Hillier, 2007:184).

Y proponemos denominar líneas de Aión a las líneas "tópicas" del espacio del deambular (Ingold, 2015:231), de los ensamblajes (Landa) algebraicos (Allen). Líneas de la Granada nazarí. De la cuadrícula norteamericana. Del Plan Cerdá. De la Ciudad Lineal de Soria (despliegue literal del círculo del tiempo). Líneas de "axialidad instrumental" que responden a unas "exigencias producción" (Hillier, Ibíd.). Líneas que constituyan (Marot, 2006:148-149) matrices territoriales más complejas, más profundas, capaces de articular la memoria estratificada de los lugares, para una ciudad que aspira a comportarse, "al mismo tiempo y explícitamente, como un teatro de profecía y como un teatro de memoria".

\section{CONCLUSIÓN. (Preliminar)}

El trazado cabal, desde el planeamiento urbano, de las líneas tópicas de Aión, de diagramas que establezcan ensamblajes algebraicos, y la articulación de estos con lo jerárquico, lo geométrico, lo actual (con las líneas de Cronos), puede servir de antídoto frente al caos y la informidad (Marot, íbid.:148) de los lugares allanados en nombre de un presente sin sustancia.

\section{OBJETIVOS.}

El objetivo de esta investigación es realizar alguna aportación a la reformulación en curso del concepto y de los modos de expresión gráfica de la planificación urbana, principalmente en su alcance territorial y general: Desde el entendimiento del sentido y operatividad de ejemplos paradigmáticos (actuales y del pasado), quizás pueda señalarse alguna recomendación para la revisión de los instrumentos clásicos de planeamiento.

Con el estudio de ejemplos nos interesa verificar si los diagramas urbanos han tenido un valor productivo. Esto es: Capacidad de generar la forma desde la diferencia (lo nuevo) en consonancia con la producción de sentido propia de cada época y lugar. A su vez, desde la hipótesis de que los diferentes diagramas urbanos presentan un desarrollo no lineal, incluso recurrente a veces, nos preguntamos si dicha producción de novedad está vinculada a una multiplicidad de tradiciones en permanente transformación (¿tipológica? ¿de patrones?) espacio-temporal. 
A su vez, al abordar la citada producción (espacial) de sentido desde la óptica de las tres ecologías (Guattari 1996), esto es: su triple acepción medioambiental, social y mental, se pretende que el estudio teórico y de ejemplos sirva para verificar la aplicabilidad de los diagramas como medio de expresión gráfica del urbanismo ecológico. Ello implica verificar sus posibles beneficios en tanto que medios para:

- La comunicación y gestión, desde el smart planning, de ideas y proceso complejos.

- Servir como instrumentos para la participación, al servir como plataformas para los procesos inmanentes (de abajo arriba) de producción y gestión de espacio urbano desde la colaboración.

En última instancia, queremos también revindicar el valor referencial del plano urbanístico (Martí 2006:17,29): Su papel como herramienta para el conocimiento y la intervención en la ciudad desde la interpretación de sus aspiraciones y deseos, y desde la reflexión disciplinar para el desarrollo de nuevos dispositivos. Y es que el plano urbanístico es también un "objeto cultural" que tiene un valor referencial: Contiene virtualidades que la realidad no está en condiciones de aportar. Es decir, establece ficciones para la producción de conocimiento (Deleuze), que orientan (dan sentido) a la producción del espacio. De lo contrario, cuando ésta es mera consecuencia de los procesos socio-económicos, el resultado es el caos y lo informe.

\section{METOdOLOGÍA.}

\subsection{Marco teórico.}

"Creo conveniente que cualquier investigación en arquitectura tome como principal objeto de estudio las obras y los proyectos en su singularidad y concreción" (C. Martí).

En la presente investigación aspiramos a desarrollar una reflexión orientada a la acción, porque el conocimiento ya no está separado de ella (Ascher, 2012:33). Y de ahí la importancia actual de la metodología heurística: Aquella que, aspirando al descubrimiento, procede por evaluaciones sucesivas e hipótesis provisionales.

Es por ello que, a efectos metodológicos, seguiremos a Martí Arís (2007:9-11) en su consideración de los ejemplos como el objeto prioritario en la investigación arquitectónica. Por tanto, concederemos a la reflexión teórica un papel relevante aunque siempre al servicio de las realizaciones, por considerar éstas como la auténtica clave de todo saber en el campo arquitectónico. Pretendemos por tanto una producción de conocimiento que "se desarrolla con el propio hacer".

Se postula entonces una teoría que toma como punto de partida el estudio concreto de los ejemplos, desde la idea de que "tras toda gran obra existe un esfuerzo reflexivo, un pensamiento teórico activo". Ello es así porque "el saber arquitectónico se inscribe y deposita en las propias obras y proyectos", ya que los conocimientos que se generan en la elaboración de los proyectos "acaban depositándose en la obra en forma de energía potencial siempre disponible". Así, en base a su labor teórica subyacente, mediante el estudio de los ejemplos paradigmáticos (en nuestro caso en materia de urbanismo) es posible poner en relación sus formas concretas con las ideas y conceptos de que aquellas se alimentan. En este punto se tendrá muy presente lo expuesto por E. Morin (1981:70), según lo cita Martí: "La teoría está abierta al universo del que da cuenta, de él extrae confirmación, y si surgen datos que la contradicen, procede a verificaciones y revisiones". Y es que "una teoría que se cierra a lo real se convierte en doctrina (...) sus axiomas entonces se convierten en dogmas".

Procederemos por tanto, siguiendo con Martí (íbid, 22), desde la consideración instrumental de la teoría, entendiéndola como "construcción auxiliar" que posibilita "ensanchar la práctica del proyecto y su campo problemático proporcionando al mismo tiempo instrumentos que permitan plantear esos problemas con mayor claridad". Se pretende así, mediante la teoría, "reconocer más ordenadamente la complejidad de lo real".

Y siguiendo a Aragüés (1998:19-25) en su revisión de la "Crítica de lo negativo" en Gilles Deleuze, no planteamos aquí un proceso dialéctico entre pensamiento y acción, teoría y práctica, sino un "pensamiento afirmativo" que es acción en sí mismo, dada su vocación productora de lo nuevo, de generación de diferencia. Vocación en nuestro caso de pensar en torno a ejemplos.

\section{Sobre la metodología para el análisis crítico.}

Toda gran obra poética, indica T.S. Elliot citado por Martí (Íbid. 17-18) "se asienta, necesariamente, en la 
reflexión crítica sobre algunas obras precedentes. Se trata pues de definir una tradición en la que insertarse y desde la que avanzar". Y desde dicha reflexión crítica se intentará "reproducir, en la medida de lo posible, el proceso mental seguido por el artífice" de cada obra, interesándonos "ante todo por el cómo, tanto por las estrategias manifiestas como por los trucos ocultos".

En este sentido, el trabajo crítico a desarrollar aquí intentará referirse a trazados urbanísticos que constituyan, si es que ello existe, una tradición diagramática.

\subsection{Consideraciones prácticas.}

El ya mencionado estudio de ejemplos se organizará de manera sincrónica y, siguiendo a De Landa (2011), descartando el concepto de evolución lineal: Partiremos de que cada proceso urbano se agrega a los anteriores, coexistiendo e interactuando con ellos sin dejarlos completamente en el pasado. Tendremos en consideración, por tanto, la existencia de tradiciones que, acumuladas al igual que los estratos terrestres, pueden volver a emerger según sean las circunstancias presentes.

En consonancia con lo anterior, la organización del estudio se apoyará en una clasificación tipológica (lo cual implica acudir a otra forma de técnica diagramática): Identificaremos diferentes familias de diagramas urbanos, en base a sus elementos básicos constituyentes ( $\mathrm{y}$ a sus híbridos), y al alcance de su huella en el territorio. Analizaremos su fundamento conceptual y el devenir de su utilización, transitando desde lo general a su uso particular como herramienta urbanística. Nos interrogaremos sobre los valores conforme a los cuales se trazaron, sobre los procesos a que daban respuesta. Así, los clasificaremos como puntos, líneas, tramas y redes, en tanto que herramientas para atender procesos de dispersión, progreso, tejido o rizomáticos. Y consideraremos una hipotética analogía con respecto a su sentido. Respectivamente: Disolución, fe, dominio y dinamismo.

Esta investigación, por tanto, plantea un estudio histórico de la evolución conceptual e instrumental de ciertas técnicas cartográficas y de dibujo en urbanismo, y del modo en que la consiguiente materialización del hábitat humano interacciona con los valores propios de su época y lugar. Se trabajará en torno a casos concretos, prestando atención al grado de novedad/especificidad presentado en cada uno de ellos.

En una segunda fase del trabajo, se pretende trasladar dicha metodología a casos recientes y contemporáneos.

Procederemos pues de abajo arriba: Partiremos del análisis de los elementos básicos constituyentes de los diagramas, y de las relaciones y dinámicas que expresan, para, en base a ello, estudiar la síntesis urbana a la que dieron lugar (o que proponían), las propiedades sistemáticas producidas.

Así mismo, para la organización tipológica se prestará especial interés a la contraposición entre la tradición geométrica (clásica), que establece un armazón formal, y la fundamentada en lógicas relacionales (no figurativas), sintácticas, algebraicas, de raíz no occidental (Allen).

La crítica del sentido de cada diagrama se realizará en base al estudio de las fuerzas que lo motivaron. Esto constituye otro criterio clasificatorio y de análisis en línea con el anteriormente expuesto: Si su traza se apoya en un poder centralizado, que posibilita la implementación de planes y con ello el establecimiento de formas a priori (trascendentes), o si es expresiva de procesos de autoorganización (inmanentes). Respecto de esta segunda casuística, consideraremos con De Landa (íbid, 14-15) que no constituyen desarrollos ciegos: Aunque sean consecuencias colectivas no intencionales de decisiones intencionales, pueden modelarse por cuanto que emergen de instituciones sociales.

Se pretende, en definitiva, esbozar una reflexión teórica, apoyada en conceptos básicos de la filosofía y, principalmente, de la teoría urbanística reciente, que será puesta a prueba y desarrollada mediante el análisis de ejemplos.

\section{HIPÓTESIS.}

La hipótesis de trabajo es la siguiente: Puede hablarse de un planeamiento diagramático de aspiración holística. Aquel que expresa no sólo relaciones espaciales y medioambientales, sino también sociales y subjetivas (mentales). Es decir: Sus grafismos ponen de manifiesto procesos físicos, máquinas abstractas (Deleuze y Guattari), que estructuran tanto la realidad material como la inmaterial (de Landa, 2011:70-71). 
Desde este punto de vista, los diagramas pueden ser herramientas proyectuales idóneas para el urbanismo ecológico, pues quizás sirvan de plataforma para la introducción de ciclos virtuosos en ese irreductible espacio contemporáneo del flujo. Pueden ser la expresión infraestructural de los procesos a activar como soporte de los nuevos paisajes que aspiramos habitar.

Siendo así, cumplirían el objetivo señalado por Guattari (1996:38) de dotar de "soporte expresivo" a los "catalizadores existenciales" que constituyen el núcleo de todas las prácticas ecológicas. 


\section{CASOS DE ESTUDIO. (Selección preliminar)}

- La Mezquita de córdoba y Non-stop city (Archizoom) como ejemplos de tramas relacionales.

- Las ciudades ideales: Los diagramas geométricos renacentistas.

- Santa Fé (Granada), Las ciudades Hispano-Americanas, la malla de Jefferson (Ley de 1785), el Plan Cerdá y Broadacre City (Lloyd Wright), como ejemplos de cuadrículas geométricas.

- Las plazas mayores, la Granada renacentista, la Barcelona Olímpica y el proyecto Energy City (de A. Ulisse), como ejemplos de diagramas de puntos (archipiélagos).

- El Camino de Santiago, en su configuración medieval, y la Ciudad Lineal de A. Soria, como ejemplos de diagramas lineales.

- La Granada y La Alhambra nazaríes, y los desarrollos en torno a las autovías europeas (segunda mitad del siglo XX) como ejemplos de diagramas anulares.

- La Regla de las 7V (Le Corbusier), y la Guía psicogeográfica de Paris (Guy Debord) como diagramas de cosido de las tramas urbanas.

- Proyecto para La Villete (Koolhaas) y para Stadtlandschaft Lichterfelde Süd, Berlin (Beigel), como ejemplos de diagramas de bandas.

- El urbanismo ecológico (I. McHargh y A. Branzi), y el POT de la Costa Gallega como ejemplos de diagramas rizomáticos.

\section{REFERENCIAS BIBLIOGRÁFICAS.}

ALLEN, S. (2009). Del objeto al campo: Condiciones de campo en la arquitectura y el urbanismo. En I. ABALOS (ed.), Naturaleza y artificio. Barcelona: GG.

ALLEN, S. (2010). Urbanismo infraestructural. En J. GARCÍA-GERMÁN (ed.), De lo mecánico a lo termodinámico. Barcelona: GG.

ARAGÜÉS, J. M. (1998). Deleuze (1925-1995). Madrid: Ediciones del Orto.

ARENAS, L. (2011). Fantasmas de la vida moderna. Madrid: Trotta.

ARENAS, L. y FOGUÉ, U. Ed. (2011). Planos de [inter]sección. Materiales para un diálogo entre filosofía y arquitectura. Madrid: Lampreave.

ASCHER, F. (2012). Los nuevos principios del urbanismo. Madrid: Alianza.

BAUMAN, Z. (2012). Modernidad líquida. Buenos Aires: Fondo de Cultura Económica.

CACCIARI, M. (2010). La ciudad. Barcelona: GG.

DELEUZE, G. y GUATTARI, F. (2013). Rizoma. Introducción. Valencia: Pre-Textos.

DOVEY, K. (2013). Assembling architecture, en H. FRICHOT y S. LOO (Ed.), Deleuze and architecture. Edimburgo: Edinburgh University Press.

EZQUIAGA, J.M. (2011). El proyecto urbano: entre la racionalidad limitada y la utopía fragmentaria. En J. M. EZQUIAGA y L. GONZÁLEZ (ed.), Transformaciones urbanas sostenibles. Vigo: U.I.M.P.

HILLIER, B. (2007). Space is the machine. Londres: Space Syntax.

INGOLD, T. (2015). Líneas. Una breve historia. Barcelona: Gedisa.

KOOLHAAS, R. (2006): La Ciudad Genérica. Barcelona: GG.

KOSTOF, S. (2014): The city shaped. Londres: Thames\&Hudson.

KWINTER, S. (2009). La arquitectura y las tecnologías de la vida. En LL. ORTEGA (ed.), La digitalización toma el mando. Barcelona: GG.

LANDA, M. (2011). Mil años de historia no lineal. Barcelona: Gedisa.

M. LOREA, I. (2013). Prólogo a La producción del espacio (H. LEFEBVRE). Madrid: Capitán Swing.

MAROT, S. (2006). Surburbanismo y el arte de la memoria. Barcelona: GG.

MARTÍ, C. (2006). De la periferia urbana a la ciudad policéntrica. En A. BARRIONUEVO (Coord.), FAU-2005. Habitabilidad y ciudad. Sevilla: E.T.S.A. de la Universidad de Sevilla.

MARTÍ, C. (2007). La cimbra y el arco. Barcelona: Fundación Caja de Arquitectos.

MARTÍN, A. (2009). Lo urbano en veinte autores contemporáneos. Barcelona: Edicions UPC.

MEAD, A. (2009). Viajeros del tiempo. En I. ABALOS (ed.), Naturaleza y artificio. Barcelona: GG.

PARDO J. L. (2011). El cuerpo sin órganos. Presentación de Gilles Deleuze. Valencia: Pre-Textos.

PICON, A. (2015). Smart Cities: A Spatialised Intelligence. Nueva York: John Wiley \& Sons Ltd.

ROJO, J. A. (2012). La filosofía como un acto radical de creación. Madrid: Babelia, 11 de febrero de 2012. SOLÀ-MORALES, I. (2002). Territorios. Barcelona: GG.

SORIANO, F. y otros (2002). Diccionario Metapolis de arquitectura avanzada. Barcelona: ACTAR.

SPERANZA, G. (2017). Cronografías. Arte y ficciones de un tiempo sin tiempo. Barcelona: Anagrama. 